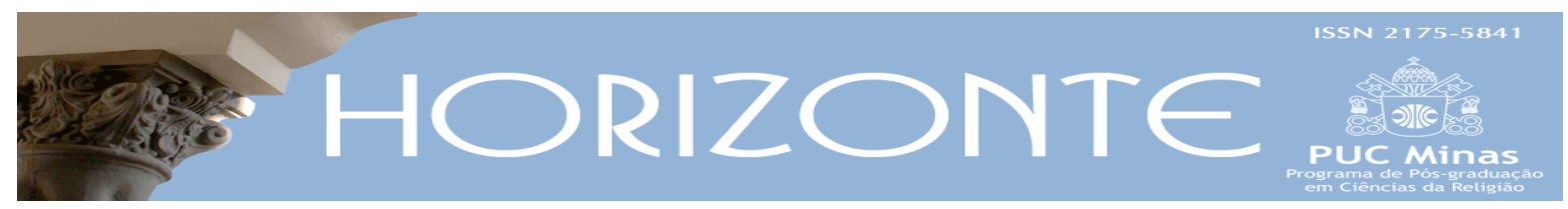

Dossiê: Política, Mídia e Religião - Artigo Original (c) (i)

\title{
Um rio de opinião subterrâneo: contrapúblicos terrivelmente evangélicos
}

\author{
An underground public opinion: \\ the Evangelical counterpublics
}

Leandro de Paula Santos*

\begin{abstract}
Resumo
Este artigo persegue dois objetivos centrais. O primeiro consiste em indicar certa representação do segmento evangélico verificável na produção de conglomerados de mídia do país na última década, que concorreu para a generalização de imaginários em torno desta identidade religiosa. O segundo propósito é apontar como essas imagens recorrentes suscitaram um discurso reativo de mídias noticiosas evangélicas a respeito da imprensa secular, questionada em sua capacidade de vocalizar o interesse público. Baseado em ferramentas de Análise do Discurso, o artigo investiga conteúdos publicados entre 2007 e 2019 pela revista Época, pelo jornal Folha de São Paulo, pela revista Cristianismo Hoje e pelo site Gospel Prime. As conclusões apontam para a emergência de uma disputa pelo sentido do "público" entre mídias seculares e religiosas, e para a crescente posicionalidade dos evangélicos frente à oferta da grande imprensa.
\end{abstract}

Palavras-chave: Mídia. Secularismo. Evangélicos. Esfera Pública. Contrapúblicos.

\begin{abstract}
This paper seeks to show a kind of representation of Evangelicalism by mainstream Brazilian press media outlets during the last decade, and how it has helped to build some ideas around that religious identity. The second purpose is to demonstrate that evangelical news media groups have reacted to such representation, and denounced the inability of the secular press to properly vocalize public interest. The paper employs Discourse Analysis resources and probes content published between 2007 and 2019 by secular media outlets (Época news magazine and Folha de São Paulo newspaper) as well as religious ones (Cristianismo Hoje news magazine and Gospel Prime website). Its findings reveal an emerging dispute around the sense of "public" by secular and religious news media groups.
\end{abstract}

Keywords: Media. Secularism. Evangelicals. Public Sphere. Counterpublics.

Artigo submetido em 29 de fevereiro de 2020 e aprovado em 22 de agosto de 2020.

* Doutor em Comunicação pela UFRJ. Professor da UFBA. País de origem: Brasil. E-mail: psleandro@ufba.br 


\section{Introdução}

Em janeiro de 2019, em seu discurso de posse no Ministério da Mulher, da Família e dos Direitos Humanos, Damares Alves afirmou que "o Estado é laico, mas esta ministra é terrivelmente cristã.” (BORGES, 2019). Logo o Presidente da República se apropriaria da tirada, repetindo em diferentes ocasiões a intenção de indicar para o Supremo Tribunal Federal um "ministro terrivelmente evangélico" (URIBE, 2019; CALGARO; MAZUI, 2019). Promovida à barganha política, a ideia de uma religiosidade que se manifesta terrivelmente insinua uma atitude ambígua, já que o advérbio é capaz de alterar a intensidade e também o modo do adjetivo. $\mathrm{O}$ resultado é uma charada: afinal, ser terrivelmente evangélico significa ser muito religioso ou ser religioso de um jeito ameaçador?

A ambivalência interessa porque se lança sobre uma identidade religiosa reivindicada por parcela considerável da população e reconhecida como cliente potencial de influentes mercados políticos e midiáticos no Brasil hoje (CARRANZA, 2020; SANT'ANA, 2013). Este artigo busca refletir sobre esse evangélico genérico, abstrato, como uma figura retórica que também tem algo a revelar quando posicionada no papel de antagonista. Proponho analisar certa imaginação em torno dos evangélicos verificável em sua representação por veículos da imprensa secular na última década, nos quais reincide o estranhamento quanto aos comportamentos e valores do grupo.

O texto avança em trilhas já percorridas por pesquisas anteriores (TORRES, 2011; CUNHA, 2016b), e sugere que o aparente êxito do enunciado "terrivelmente evangélico" - a eficácia de sua sugestão no quadro de um governo polemista guarda afinidade com uma história organizada em dois eixos principais. Primeiro, o deslocamento dessa religiosidade em relação a padrões cívicos defendidos por poderosos meios de comunicação do país. Em segundo lugar, o desenvolvimento do circuito das mídias religiosas digitais, no qual a identidade evangélica genérica tem se tornado esteio para práticas contrapúblicas. (WARNER, 2002) 
O pano de fundo para tal esforço é a ascensão desse segmento religioso no jogo partidário, nas mídias de massa e em outros espaços de influência, tema amplamente investigado nas Ciências Sociais. Iniciada como projeto há mais de três décadas (FRESTON, 1992), a ocupação evangélica da política institucional tornou-se força ainda mais evidente com a crise instalada desde o impeachment de Dilma Rousseff. Almeida (2017) insiste que uma onda conservadora teria se formado nessa cena histórica recente, reunindo tendências meritocráticas, repressivas, moralmente reguladoras e socialmente intolerantes existentes entre o segmento evangélico. Já Camurça (2019, p. 98) sustenta que uma "ofensiva de confessionalização do Estado" estaria a se desenrolar no governo Bolsonaro, concentrada nas áreas "das relações exteriores, dos direitos humanos, da cultura e do conhecimento".

Amparado por tais reflexões, sugiro que, no Brasil recente, é o próprio sentido do "mundo público" que se encontra em disputa por discursos seculares e religiosos, cumprindo as mídias noticiosas o papel de estabelecer condições expressivas para o conflito. Assim, em vez de colocar a questão da presença evangélica sob a perspectiva da "intromissão" no que não diria respeito à religião (as políticas públicas, a organização do Estado, a moralidade coletiva etc.), proponho observar a constituição agonística do secularismo brasileiro e a agência essencial que nele têm as mídias (PAULA, 2016).

Para acessar essas diferentes dimensões do problema, o artigo se divide em duas seções principais. Primeiramente, são analisados reportagens e textos de opinião sobre os evangélicos divulgados em diferentes momentos da última década pelo jornal Folha de São Paulo e pela revista Época. Tais veículos são tomados aqui como referências da imprensa de prestígio, assim definida pela capacidade de ter seus conteúdos replicados por outras mídias e influenciar mesmo as classes que não a consomem, uma "popularidade advinda de seu reconhecimento pela elite." (CHAGAS, 2017, p. 38). Já na segunda seção, são exploradas transformações do mercado midiático evangélico, e comentados conteúdos que ilustram linhas da percepção do segmento sobre a vida pública brasileira no mesmo período histórico. 
Investigam-se aí materiais de Cristianismo Hoje, revista de referência para o nicho no início dos anos 2010, quando chegou a imprimir 40 mil exemplares por edição (SIMAS, 2010), e do site Gospel Prime, um dos maiores portais religiosos do Brasil hoje, com cerca de 2,8 milhões de leitores ao mês. (BORGES, 2018).

O trabalho destaca temas e formas empenhados por tais veículos, utilizando como chave metodológica a analítica de Michel Foucault (2008, p. 55): “certamente os discursos são feitos de signos; mas o que fazem é mais que utilizar esses signos para designar coisas. É esse mais que os torna irredutíveis à língua e ao ato de fala. E esse 'mais' que é preciso fazer aparecer e que é preciso descrever”. Seguindo essa lição, o texto assume que o litígio entre diferentes mídias noticiosas pode dar testemunho da constituição mútua do religioso e do secular como configurações de poder (ASAD, 2003). Mostrar como as palavras fazem mais do que designar coisas requer desconfiar do caráter neutro de cada enunciado e, ao mesmo tempo, duvidar que jornalistas ou articulistas sejam os autores conscientes do discurso para cuja formação cooperam. Com Foucault, podemos postular a existência de objetivos que atravessam esses enunciados à revelia de seus sujeitos vocais, e que a tarefa hermenêutica consiste em desvendar as condições políticas pelas quais os discursos ganham força e função em uma época.

\section{Evangélicos e mundo público}

A relação entre os evangélicos e a vida pública no Brasil teve início quando da chegada de missionários protestantes ao país no período imperial, cujos periódicos confessionais circularam novos valores e ideias entre uma coletividade que então formava seu senso como nação. Esse fato integra a remota história de constituição de nossa esfera pública, aqui pensada como uma arena discursiva na qual se negocia o destino da comunidade política (HABERMAS, 2003). A embrionária imprensa secular brasileira não tardaria a registrar o deslocamento daquela sensibilidade religiosa no âmbito da imaginação pública: "o protestantismo foi tratado pela imprensa periódica secular e conservadora como um elemento 
estranho, avesso à ordem e às estruturas da nação brasileira” (SILVA, 2015, p. 86), reflexo da orientação católica dos formadores de opinião.

Foi apenas com o declínio da ditadura militar, já nas décadas de 1970 e 1980, que se consolidou no país um jornalismo a um só tempo comercial e crítico, aplicado na defesa de ideais democráticos, laicos e liberais (COSTA, 1997). Trata-se do mesmo contexto da afirmação do pluralismo religioso no país, na esteira da Constituinte, que propicia uma nova cena ética para a atividade jornalística frente aos temas concernentes à religião.

O lastro eleitoral evangélico nas campanhas majoritárias, notável ao menos desde o pleito de $2002^{1}$, assumiu um novo patamar de visibilidade quando, em 2010, Dilma Rousseff enfrentou forte resistência de setores conservadores por sua opinião favorável à legalização do aborto. A posição pessoal da candidata petista sobre o tema, assumida em uma entrevista, foi instrumentalizada pela campanha de José Serra, gerando uma controvérsia nas páginas da imprensa.

“Deus entrou na eleição", reportagem de capa da revista semanal Época, pertencente ao Grupo Globo, é uma amostra significativa de como os evangélicos então se consolidavam como fator político na ótica do jornalismo de prestígio. Publicada entre os dois turnos da votação, a matéria registrava certo espanto diante de um novo circuito de influenciação de eleitores, baseado em pautas morais altamente mobilizadoras. Essa máquina política, ancorada na sensibilidade religiosa e capilarizada por igrejas e canais da internet, explicaria a repentina perda de votos da candidata petista:

Foi como se um imperceptível rio de opinião subterrâneo se movesse contra Dilma. Esse rio tirou milhões de votos dela e os lançou na praia de Marina Silva, a candidata evangélica do PV. [...] A elevação do padrão de vida dos pobres e a superação das necessidades elementares de sobrevivência podem ter começado a abrir espaço para aquilo que, em democracias mais maduras, é conhecido como "agenda de valores". (MARTINS; ROCHA, 2010).

\footnotetext{
${ }^{1}$ Utilizando sua filiação religiosa como bandeira de campanha, o ex-Governador do Rio de Janeiro Anthony Garotinho alcançou o terceiro lugar no primeiro turno, com mais de 15 milhões de votos.
} 
Um hiato se detectava ali entre a "opinião pública brasileira”, da qual Época implicitamente se colocava como porta-voz, e um "rio de opinião subterrâneo" religiosamente orientado. A reportagem pressentia uma cena política em gestação, na qual as camadas mais populares do país se mostravam reféns de imprevisíveis agendas, como exemplificava o desempregado Otacílio Soares, membro da Casa da Bênção de Jacarepaguá.

A onda emocional que Dilma está enfrentando pode ser avaliada pelo depoimento do evangélico carioca Otacílio Galdino Soares, de 34 anos. Ele diz que planejava votar em Dilma no primeiro turno - "por causa de Lula" -, mas mudou de ideia. "Ouvi na igreja que ela é a favor do casamento gay, isso é uma coisa abominável aos olhos de Deus", diz Galdino. (MARTINS; ROCHA, 2010).

Embora contasse com a participação ferrenha de militantes católicos (LUNA, 2014), a "onda emocional" que ameaçava a candidatura de Dilma comparecia nas páginas da revista pela representação das disposições eleitorais dos evangélicos, que seriam tanto voláteis quanto subservientes àquilo que ouviam nas igrejas. Ao remeter ao campo das emoções a formação de juízos por parte desse grupo religioso, a revista contribuía ainda para a sugestão de seu desalinho com aqueles capazes de usar a razão para definir o próprio voto. Pois, como lembra Efrem Filho, as fronteiras entre "nós" e os "evangélicos" tendem a ser produzidas por uma dualidade comum em contextos de discriminação por raça ou gênero: "o 'outro emotivo' e 'racionalmente deficiente' tem suas capacidades intelectivas e, logo, sua humanidade sob suspeita”. (EFREM FILHO, 2019, p. 126).

O discurso secular de Época endereçava seu público por contraste, presumindo a natureza não evangélica do mundo compartilhado por seus leitores. A revista buscava retratar certo fenômeno para uma audiência imaginada, construída pelos valores de sua abordagem do segmento. Ressalto aqui certa qualidade ficcional da comunicação mediada, lembrando que "públicos não existem à margem do discurso que se dirige a eles." (WARNER, 2002, p. 416; tradução minha). Na perspectiva de Michael Warner, uma audiência se transforma em um público na medida em que um discurso a aborda como um atributo normal 
da vida social. Para o autor, "todo discurso ou performance destinado a um público deve caracterizar o mundo em que busca circular, assim como tornar real esse mundo pela forma como o endereça”. (WARNER, 2002, p. 422; tradução minha).

Outro exemplo originado das páginas de Época mostra uma tentativa de descrição do segmento como uma comunidade moral, pautada por valores e atitudes específicos. Publicado em 2011, o artigo "A dura vida dos ateus em um Brasil cada vez mais evangélico", de Eliane Brum, relata uma conversa entre a jornalista e um taxista. Brum tece o perfil do motorista como um jovem de pouca escolaridade, com o qual procura travar uma conversa civilizada sobre o tema da religião. O taxista confessa escrever "tudo errado" e se mostra entusiasmado com a perspectiva de melhorar seu português lendo a Bíblia. Conversando com o rapaz, a jornalista afirma ser ateia, ao que o taxista responde “Deus me livre!”. Brum é então convidada para visitar a igreja Novidade de Vida, frequentada pelo jovem, mas declina, destacando a indisposição do motorista em aceitar seu direito de ser diferente.

$\mathrm{O}$ artigo pondera como "essa porção cada vez mais numerosa do país está mudando o modo de ver o mundo e o modo de se relacionar com a cultura. Está mudando a forma de ser brasileiro”. Para Brum, o jovem taxista seria exemplo de um grupo “doutrinado para acreditar que um ateu é uma espécie de Satanás”. Essa seria uma particularidade dos evangélicos, tendo em vista que o catolicismo “mantém uma relação de tolerância com o ateísmo. Por várias razões. Entre elas, a de que é possível ser católico e não praticante. Ser ateu num país de maioria católica nunca ameaçou a convivência entre os vizinhos. Ou entre taxistas e passageiros”. (BRUM, 2011).

Diante dessa herança, o tipo de filiação dos evangélicos soaria ostensivo, uma vez que, diferente da relação com a Igreja Romana, "não há como ser um evangélico não praticante." (BRUM, 2011). Por isso, segue o artigo, os ateus "têm preferido declarar-se 'agnósticos'. Com sorte, parte dos crentes pode ficar em dúvida e pensar que é alguma igreja nova”. Para Brum, o crescimento da 
intolerância seria um dos efeitos da atitude evangélica em nosso espaço público, “alterando o 'homem cordial' - não no sentido estrito conferido por Sérgio Buarque de Holanda, mas no sentido atribuído pelo senso comum". Na ótica dessa formadora de opinião, os evangélicos cresciam assim como um corpo estranho em meio ao tecido social. Sua inabilidade em agir no mundo público de acordo com os códigos culturais da brasilidade resultaria em um comportamento proselitista, uma forma estrita de adesão que conflitaria com o que o catolicismo estabelecera por modelo de cidadania religiosa no país.

Outro caso sugestivo da relação entre a imprensa de prestígio e os evangélicos se fez notar na Folha de São Paulo, em um alerta assinado por Suzana Singer, que ocupava em 2013 o posto de ombudsman do jornal. Esse cargo garante estabilidade a um jornalista para que exerça a crítica do próprio veículo, representando os leitores e o interesse público dentro de um órgão de imprensa. Singer sinalizava em seu texto a parcialidade da cobertura da Folha, assim como de outros jornais brasileiros, sobre a presidência da Comissão de Direitos Humanos da Câmara, ocupada por Marco Feliciano:

Daniela Mercury, Caetano Veloso, Fernanda Montenegro, Wagner Moura, Yasmim Brunet... gente bonita e famosa já expressou, com palavras e beijos, o inconformismo com a permanência do Deputado Marco Feliciano na presidência da Comissão de Direitos Humanos e Minorias da Câmara dos Deputados. Cada um desses protestos ganhou amplo espaço na mídia. Mais difícil é ouvir argumentos a favor do pastor. [...] A impressão que se tem, lendo jornais, revistas e navegando na internet, é que há unanimidade contra o deputado do PSC. Falta dar espaço às vozes dissonantes daqueles que criticam a cobertura da mídia e se recusam a entrar na corrente "antiFeliciano". (SINGER, 2013).

O texto passa então a elencar mensagens recebidas de leitores, com críticas à maneira como Feliciano era retratado na Folha. A advogada Patrícia Marinelli, por exemplo, dizia que "o jornal não cita a profissão de nenhum parlamentar, mas Feliciano é sempre 'pastor', o que impõe uma carga pejorativa à palavra. Há um estereótipo do evangélico repetido à exaustão na mídia”. Argumento semelhante era levantado pelo servidor público Samuel Lourenço: "se Feliciano fosse padre, a 
imprensa não faria esse estardalhaço”. Já para o tradutor Carlos Alberto de Paula, haveria "uma campanha invisível, porém sensível, para atrelar a figura genérica de qualquer pastor e qualquer evangélico às visões do deputado. É uma Inquisição, que visa tornar o termo 'evangélico’ sinônimo de intolerante.” (SINGER, 2013). Via-se então a posição consciente de parte do leitorado quanto a um regular tratamento da identidade religiosa pelo jornal. Na conclusão do texto, Singer afirmava ser "importante reconhecer que a cobertura do caso Feliciano ganhou ares de linchamento. E não há dúvida de que existe na grande imprensa brasileira uma visão estereotipada e preconceituosa dos evangélicos”. (SINGER, 2013).

Meses após realizar essa autocrítica, o jornal apostaria na comunicação online lançando um blog intitulado "Religiosamente". A proposta da plataforma, segundo seu texto de apresentação, seria abordar "o fascinante mundo das certezas religiosas”. Para tanto, o texto prometia especial atenção aos evangélicos, dada sua relevância para nossa dinâmica social: "a ideia não é julgar. É escrever sobre um Brasil que está mudando”. Esse senso de mudança do panorama religioso brasileiro justificaria o enfoque em "um segmento tão emergente e, ao mesmo tempo, tão pouco compreendido por quem é de fora”. Para sanar essa defasagem no debate público, o blog propunha acessar a experiência evangélica de perto, ou seja, "ir lá, sem réguas ideológicas, e conhecer um pouco da realidade deles”. (BALLOUSSIER, 2013a, grifos do autor).

Os títulos das postagens da plataforma são indicativos: "PMs de Cristo contra o baixo-astral", sobre uma capelania que presta assistência a policiais militares evangélicos; "Pornô evangélico pode?”, sobre a relação dos evangélicos com a pornografia; "Programa de Aceleração do Credo", sobre a aproximação entre representantes do segmento e o então Prefeito de São Paulo, Fernando Haddad. Na abordagem de um caso de intolerância religiosa sofrida por uma criança umbandista despontava o desencontro entre evangélicos e os valores da brasilidade: “o 'chuta que é macumba' parece mais forte entre os neopentecostais. É aí que desafina o Brasil miscigenado, ecumênico e religiosamente sincretizado”. (BALLOUSSIER, 2015). 
Outro conteúdo narra a visita à Feira Literária Internacional Cristã, evento que comercializava o livro "Celebração do Sexo". Do livro, o blog destaca apenas a ideia de que o prazer sexual seria "um presente de Deus no casamento”, com "um capítulo inteiramente dedicado ao sexo feito "sem tirar a roupa" (BALLOUSSIER, 2013b). A moralidade sexual evangélica renderia também a abordagem sobre um movimento de jovens que abraçam a proposta da castidade: segundo o blog, "ninguém deve transar antes do matrimônio, pois diz a Bíblia que se abster da ‘fornicação' é ‘a vontade de Deus”. A apresentação de uma das integrantes do movimento, uma jovem de 18 anos decidida a "não fornicar", é feita nos seguintes termos: "com brincos da Minnie e aparelho odontológico no sorriso, Larissa é toda ouvidos à mensagem casta: 'A gente pode ser chamado de louco, mas é uma escolha"”. (BALLOUSSIER, 2014).

O blog "Religiosamente" amplia as evidências da representação visada nesta seção, e também já sugerida por outros estudos (TORRES, 2011; PAULA, 2016), pelo tenaz empenho em torno de uma percepção alteritária da identidade evangélica. Autorizado pelo registro do humor no retrato do "fascinante mundo das certezas religiosas”, o projeto prescreve um público pela permanente antinomia quanto à experiência em foco: do "sexo sem tirar a roupa" aos "PMs de Cristo contra o baixo-astral", interessa à linha editorial maximizar o exótico do comportamento evangélico. Com o interesse de "conhecer um pouco da realidade deles" e "não julgar", a plataforma que afirma cobrir os evangélicos "sem réguas ideológicas” impõe um conjunto de filtros para ler o "Brasil que está mudando”.

Pelos exemplos comentados, pode-se inferir que o deslocamento evangélico dentro do público imaginado pela imprensa se faz sobre uma dupla hostilidade de fundo. A representação do evangélico-tipo alude a determinações de classe social e 
também de capital cultural ${ }^{2}$ que inabilitariam esse ator religioso a realizar escolhas autênticas. As condições materiais e simbólicas descritas lançam o evangélico para fora do mundo presumido do público dos enunciados: o desempregado que frequenta a Casa da Bênção; o taxista que sonha em aprimorar o português; os ignorantes que desconhecem a palavra "agnóstico"; os jovens que evitam a "fornicação". Seria ainda simplista, contudo, ver nesse fenômeno o mero preconceito de uma elite intelectual cuja percepção da realidade, vocalizada pela imprensa, requer a ridicularização dos comportamentos de classe que abomina. Os discursos que enquadram os evangélicos como "outros" sintomatizam, antes, como essa identidade desafia os modelos consagrados da cidadania religiosa no Brasil.

Engajados em causas políticas e morais afins, agentes católicos têm chamado menor atenção em nosso debate público, o que demonstra o escopo limitado das análises da conjuntura e faz "parecer que a face religiosa do conservadorismo brasileiro é evangélica.” (CALDEIRA; TONIOL, 2020). Em meio aos impasses pressentidos desde a cena religiosa, as particularidades da afiliação católica podem ser assim recuperadas como virtude: uma religiosidade "que nunca ameaçou a convivência entre vizinhos", como uma dimensão quase natural de nossa civilidade e cultura. Já em 2003, Birman identificava que, com os evangélicos, emergia também “uma percepção nova e generalizada sobre 'quem somos nós', 'os brasileiros', historicamente considerados em narrativas que privilegiam a nossa catolicidade essencial”. Dessa forma, a identidade evangélica “como um 'grande grupo' exterior à imagem nacional dominante vem, pois, alterando a consciência religiosa do país e o imaginário da nação”. (BIRMAN, 2003, p. 236).

O problema talvez possa ser retomado ao considerarmos a transitoriedade de nossos regimes de percepção do ambiente público, como sugere a ideia de um sensório secular. A noção permite pensar na existência de uma "tensão produtiva

\footnotetext{
${ }^{2}$ Uso aqui a expressão "capital cultural" no sentido a ela atribuído por Pierre Bourdieu, qual seja, a de uma disposição ao desempenho cognitivo/intelectual/escolar condicionada pela classe social a que pertence um indivíduo, a qual reproduziria as desigualdades dos contextos de formação propiciados pela família. Ver, por exemplo: BOURDIEU, Pierre. Les trois états du capital culturel. Em: Actes de la Recherche en Sciences Sociales, 30:3-6, 1979.
} 
entre o religioso e o secular de modo a gerar novas práticas através de um processo de auto-diferenciação interna.” (HIRSCHKIND, 2017, p. 185). Sublinham-se aí a relação dinâmica entre as duas categorias e a plasticidade das fronteiras que tornam esses domínios da experiência moderna particularmente instáveis. Com essa ideia em mente, podemos arriscar que a visibilidade evangélica, percebida como uma forma saturada do religioso, tende a fomentar a naturalização da marca católica no mundo público e seu embaralhamento com o secular.

Ao posicionar a religiosidade evangélica como ostensiva, estaria a imprensa recente meramente ecoando aqueles periódicos do século XIX, que viram nos imigrantes protestantes "um elemento estranho, avesso à ordem e às estruturas da nação brasileira” (SILVA, 2015, p. 86)? As distintas configurações das duas cenas históricas impedem a equivalência, mas abrem uma via de reflexão. Se, no Brasil Império, a cosmovisão dos missionários ameaçava um secular incipiente, em um quadro de simbiose entre Estado e Igreja, o secular hoje alicerça o discurso público da imprensa, que reivindica para si o papel de poder moderador da democracia. Parece, portanto, que as especificidades constitutivas do secular no Brasil teriam se tornado capazes de modelar o sentido da esfera pública, delimitando as arenas e vozes legítimas para o debate dos rumos da comunidade política.

Como será que se constrói o descompasso entre esse suposto e a "onda conservadora" recente, animada por paixões religiosas como aquelas “terrivelmente evangélicas”? A próxima seção inverte o percurso de análise proposto até aqui, buscando pistas em meio às transformações do mercado midiático religioso.

\section{Os evangélicos e a "extrema imprensa"}

Vimos que a imprensa secular brasileira não raramente nega aos evangélicos o status de público, ou seja, a possibilidade de ser parte de um mundo comum pela forma como o discurso endereça seus destinatários legítimos (WARNER, 2002). Isso não é dizer, contudo, que a experiência compartilhada pelo segmento se 
ressinta da ausência de meios expressivos. Pelo contrário, a história do protestantismo se confunde com a das mídias, a ponto desse espectro ser notável justamente pela "avidez para com o domínio e utilização de modernas tecnologias de comunicação para fins de evangelização”. (JUNGBLUT, 2002, p. 150).

A trajetória desse campo no Brasil não fugiu à regra: já no século XIX, uma ativa imprensa confessional surgiu no país como meio de divulgação e defesa de princípios religiosos. Os usos evangélicos do rádio e da televisão no século XX, mapeados por Campos (2004), são também amostra do interesse do segmento pelos recursos tecnológicos de cada época em prol da atitude evangelística. Pode-se dizer, portanto, que desde há muito a religiosidade evangélica brasileira não se realiza apenas nos templos e cultos, mas também nas mídias que prolongam seu ideário por diferentes tempos e espaços.

A contribuição da história mais recente a essa antiga dinâmica relacional tem a ver com o que Cunha (2004) chamou de explosão gospel: a criação de formas de percepção e entretenimento próprias de uma cultura evangélica. Isso porque as últimas décadas estabeleceram uma nova cena para o relacionamento do segmento com as mídias, na qual experiências de consumo e lazer permitiram aos evangélicos a negociação de uma existência cindida entre céu e terra. Essa tendência se fez notar, por exemplo, nos programas religiosos de rádio e TV, já não mais exclusivamente dedicados a pregações ou ao testemunho de curas e exorcismos, mas também a atrações de auditório, números musicais, entrevistas e debates. O mercado das mídias impressas igualmente viu seu escopo se ampliar, com o aparecimento de revistas de "variedades evangélicas" (CUNHA, 2004). A ideia é significativa por indicar o horizonte editorial abrangente das publicações, desimpedidas de amarras denominacionais e do afã evangelístico. Em 2004, Cunha sinalizava a expansão desse nicho, registrando que publicações do tipo passavam a ser vendidas em bancas de jornais, em vez de serem comercializadas "apenas por meio de assinatura ou compra de exemplares avulsos em livrarias especializadas”. (CUNHA, 2004, p. 204). 
Surgida em 2007, a revista Cristianismo Hoje tornou-se referência nesse mercado e alcançou já em 2010 o posto de "principal revista de informação cristã com venda em bancas do país”. (FERNANDES; SIMAS, 2016). Versão local de Christianity Today, publicação fundada pelo pastor Billy Graham, a revista afirmava a "busca incessante pela independência editorial" e o compromisso em oferecer "reportagens, artigos e colunas que expressam a diversidade do pensamento evangélico brasileiro”. Sustentada pela venda de espaços publicitários e orientada pela missão de atender à demanda do segmento evangélico por "informação com isenção", Cristianismo Hoje reivindicava os objetivos de “informar, encorajar, unir e edificar a igreja brasileira”. (SIMAS, 2007, p. 6).

Cristianismo Hoje buscava promover uma espécie de "debate público evangélico”, apresentando-se como um espaço de reflexão e crítica do segmento por ele mesmo. A revista não se posicionava então como concorrente ou refratária ao discurso da imprensa secular; pelo contrário, emulava o registro do jornalismo de prestígio, com uma linha editorial sóbria e empenhada no ideal da “independência”. Esse projeto se fazia notar, por exemplo, em um artigo especial já no número de lançamento, no qual o pastor Ed René Kivitz afirmava que a igreja evangélica brasileira era então chamada a escolher entre duas agendas. Por um lado estaria um projeto evangelical 3 , que enfocaria o ser humano e suas circunstâncias, ou seja, sua "realidade social, política, cultural e espiritual, respeitando a pluralidade ética e cultural do Cristianismo histórico” (KIVITZ, 2007, p. 25). Por outro, estaria a hegemônica agenda fundamentalista, que sobrevive "de eventos, programas e projetos voltados para o público interno, bem doutrinado e bem comportado, à espera do céu”. (KIVITZ, 2007, p. 25).

O interesse da publicação para o artigo está em sua assumida proposta de abrigar "a diversidade do pensamento evangélico brasileiro". A revista servia como uma amostra das ambivalências dessa identidade religiosa por agrupar suas expressões progressistas e conservadoras em torno da proposta de "unir e edificar a

${ }^{3}$ Em alusão ao projeto eclesiológico da Missão Integral. Ver síntese na nota seguinte. 
igreja brasileira”. Nesse projeto editorial, cabiam, por exemplo, a descrição crítica do "abuso espiritual” infligido por “pastores que oprimem” (BRANDÃO, 2009b, p. 18), a denúncia às formas de violência contra a mulher nas igrejas (SCHWENGBER, 2009a, p. 14-16) e o endosso aos valores da Missão Integral4 (BRANDÃO, 2009a, p. 48-49). Por outro lado, Cristianismo Hoje também sancionava as ações missionárias na Amazônia da ONG Atini, fundada por Damares Alves (GONÇALVES JR.; SCHWENGBER, 2007, p. 10-14), as críticas à "flexibilização liberal” das Escrituras (FERNANDES, 2008, p. 56) e as iniciativas de pais cristãos que educavam seus filhos em casa por discordarem "dos valores morais transmitidos nos currículos e no ambiente escolar". (SCHWENGBER, 2009b, p. 18).

A heterogeneidade de temas e posicionamentos vocacionava a publicação a contribuir para a moderação da "opinião pública evangélica”, já que submetia às exigências do debate crítico impasses teológicos e morais aparentemente vividos pela audiência. Essa revista de "variedades evangélicas” exemplifica o alargamento das funções da mídia religiosa nas últimas décadas: dilemas da formação de pastores, questões bioéticas ou tensões da política institucional eram nela abordados desde a reivindicada proposta de "isenção". Em um circuito discursivo alternativo ao da imprensa secular, ainda que não antagônico a ela, Cristianismo Hoje propunha aos evangélicos um lugar como público ao tratar as contradições próprias do pensamento desse grupo religioso como um atributo normal da vida social. (WARNER, 2002).

O noticiário e o articulismo da publicação dão pistas também de como as sensibilidades políticas e morais do segmento viam-se desafiadas por um novo momento do secularismo no país, provocado pelas propostas modernizantes dos primeiros governos de centro-esquerda após a redemocratização. Cristianismo Hoje mostrava-se titubeante, por exemplo, quanto às mudanças em curso no plano dos costumes e, em especial, aos ascendentes consensos públicos em torno da

\footnotetext{
${ }^{4}$ Movimento surgido nos anos 1970 entre lideranças da Fraternidade Teológica Latino-Americana, que defendia uma missão para a igreja cristã articulada entre as ações evangelística e social.
} 
sexualidade: a revista resistia a propostas mais abertamente favoráveis à população LGBT, como o projeto de lei 122/2006, que visava a criminalizar a homofobia. (SCHWENGBER, 2007, p. 8-12).

Foi assim que os conflitos de acomodação dos evangélicos nesse novo ambiente social passaram a pautar, na revista, a representação do grupo como uma minoria cerceada. "O Fantasma da Intolerância”, matéria de capa de 2009, por exemplo, comentava a abordagem da imprensa sobre os evangélicos destacando que o segmento sentia-se "alvo, no mínimo, de má-vontade" (MACHADO; FERNANDES, 2009, p. 14). Ouvido pela reportagem, um jornalista membro da Igreja Metodista, contudo, discordava que houvesse intolerância ao grupo no debate público de então: em sua opinião, “a mídia só exerce seu papel de expor a realidade” (MACHADO; FERNANDES, 2009, p. 18).

Quatro anos depois, um artigo do teólogo Lourenço Stelio Rega intitulado "Evangélicos sob Inquisição” já aventaria outra experiência para o segmento, ao denunciar "uma campanha generalizada da mídia e de segmentos da sociedade que também têm forte apelo e acesso aos meios de comunicação de massa, incluindo-se a internet, contra quase qualquer opinião que seja originária do meio religioso, especialmente do segmento evangélico”. Rega apontava, por exemplo, a parcialidade do debate sobre identidades de gênero na imprensa secular da época, que negligenciaria a "constituição neurobiogenética e a funcionalidade diferencial que se tornam fatores fundantes e identitários da pessoa”. (REGA, 2013).

$\mathrm{O}$ artigo dava contornos a um sentimento difuso que parecia se formar entre esse público acerca de uma suposta perseguição a suas convicções: "aumenta na sociedade e na mídia o patrulhamento à expressão de fé cristã e bíblica”. Segundo o teólogo, já não era "possível, em alguns círculos, que qualquer religioso, notadamente evangélico, movido por razões de crença e consciência, emita sua opinião livremente sem receber a pecha de preconceituoso”. A imprensa teria "grande participação nesse processo de convencimento social, na medida em que 
faz germinar o estereótipo do evangélico como alguém extremado, esquizofrênico, mentalmente desajustado". (REGA, 2013).

O artigo de Rega foi publicado em 2013, mesmo ano em que os leitores da Folha de São Paulo acusariam o veículo de um jornalismo "que visa tornar o ‘evangélico' sinônimo de intolerante” (SINGER, 2013). Este foi ainda o ano no qual manifestações de rua deram início a uma prolongada experiência de crise no país, que "ocorre tanto no plano do sistema político como também desceu para as relações interpessoais", com a radicalização das "cisões entre opiniões e posições políticas e morais" (ALMEIDA, 2017). Se Cristianismo Hoje não nascera em necessário antagonismo à imprensa secular, o senso de alienação de seu público em relação a pautas então em debate pela grande mídia aparentemente cooperou para o surgimento desse espírito de concorrência. Os evangélicos e suas mídias, afinal, também são parte das chamadas guerras culturais que caracterizam a conflitualidade do espaço social brasileiro nos últimos anos.

Nesse ambiente em esgarçamento, a moderação do debate público evangélico proposta por Cristianismo Hoje parece ter perdido lugar frente à polarização das posições políticas, como indica o fim da circulação da revista em 2016. Os conteúdos publicados durante seus nove anos de existência se transformaram então em objeto de uma parceria com o grupo capixaba Comunhão, plataforma multimidiática abertamente conservadora e popular, que reivindica para si o título de "a revista da família cristã”. Um caso que exemplifica o declínio mais recente das publicações impressas diante da popularização de "processos interativos tornados possíveis pelas mídias digitais" no mercado evangélico (CUNHA, 2016a). Os bastidores desse universo midiático parecem assim dar acesso a transformações ocorridas no consumo de conteúdo religioso no Brasil, bem como nas formas de identificação produzidas em torno do segmento. 
Para seguir a análise da relação entre evangélicos e mídias noticiosas, insisto na questão da constituição do grupo como público, "um espaço social criado pela circulação reflexiva do discurso." (WARNER, 2002, p. 420; tradução minha). A ideia de Warner indica que públicos se formam não pelo fato de um texto isolado os abordar, mas sim pela concatenação de textos que lhes são endereçados ao longo do tempo. Ou seja, pelo vínculo entre textos que, mesmo dispersos cronologicamente, compõem entre si um ambiente de responsividade e interação de referências. A revista Cristianismo Hoje é ilustrativa de como se forjou, uma década atrás, uma reflexividade supradenominacional entre faces ambíguas do segmento evangélico: empática às vítimas de violência, mas ciosa do direito à homofobia; sensível às desigualdades sociais, mas devotada à conversão de índios. Os conteúdos que endereçavam essas ambivalências formavam assim um público como espaço virtual para o encontro com certo discurso evangélico.

Como pensar esse circuito reflexivo em contraponto com o público organizado em torno da imprensa secular? Para abordar essa relação, vale lembrar que a consolidação das "variedades evangélicas" acabou por atribuir a mídias religiosas a função de produzir não apenas músicas, filmes ou novelas. Sob o impacto das transformações dos processos comunicativos na última década, as notícias também parecem vir sendo apropriadas como mercadoria pela indústria do entretenimento gospel.

Embora sejam raros no Brasil os estudos sobre a recepção da mídia secular pelos evangélicos (TORRES, 2011), as pesquisas de Bakker (2006) e Oosterban (2003) trazem dados instigantes sobre como comunidades pentecostais lidavam, no início dos anos 2000, com programas da TV aberta. Em tais estudos, o ideal de afastamento das "coisas do mundo" se manifesta sob a forma de uma condenação dos conteúdos da mídia secular: personagens de novelas e programas de humor são apontados pelos entrevistados de modo contrastivo com suas próprias vidas, como referências pelas quais criticam a sociedade e seus vícios. Os grupos pesquisados encenavam um consumo seletivo e hesitante das mídias, embora uma exceção fosse consensual em ambos os estudos: "a referência ao telejornal como um tipo de 
programa que não oferece nenhum risco significativo para o olhar crente”, baseada na convicção de que as informações ali veiculadas são neutras, "falam um real objetivo, conectam o telespectador aos 'fatos' do mundo". (BAKKER, 2006, p. 74).

Resgato tais achados etnográficos para destacar que essa autoridade do jornalismo secular pode vir perdendo sentido entre os evangélicos nos últimos anos. As mudanças trazidas à comunicação social pela diversificação dos usos da internet ampliam sensivelmente a oferta de circuitos informacionais e de leituras disponíveis sobre os "fatos do mundo". Seria assim de se esperar que essas transformações também remodelassem o mercado de "variedades evangélicas", instituindo novos modelos de consumo e relação com conteúdos noticiosos.

Jungblut (2002) documentou o nascimento da internet evangélica no Brasil no início dos anos 2000, mostrando que os endereços então populares entre o segmento eram de dois tipos: páginas institucionais (igrejas, editoras etc.) e pessoais, organizadas em torno de testemunhos de fé e referências bíblicas. $\mathrm{O}$ autor não escondia a decepção com a forma e o teor dessas páginas: "não se vê nelas nada que outras formas de comunicação utilizadas pelos evangélicos não disponibilizem e, em muitos casos, com mais eficiência e atratividade do que na web." (JUNGBLUT, 2002, p. 151). Naquele início de século, a novidade trazida pela mídia ao filão religioso se manifestava em outros ambientes, como salas de bate-papo e listas de e-mail. Neles se verificava o esmero de muitos usuários "em demonstrar capacidades de desconstrução crítica do discurso dos interlocutores com quem se deparam nas controvérsias que surgem”. (JUNGBLUT, 2002, p. 153).

A dinâmica interativa detectada pelo autor nas salas de bate-papo e listas de e-mail acabou por se revelar a base para a expansão das mídias on-line nos últimos anos, como veio a atestar o êxito das redes sociais. Com elas, a ecologia midiática do século XXI alterou de modo determinante a experiência social, e multiplicou os canais para o consumo de conteúdo informativo e a elaboração de juízos sobre a realidade. Noções recentes como fake news e pós-verdade nos lembram "o fato de versões alternativas da realidade conseguirem se tornar competitivas com aquelas 
produzidas pela mídia especializada", dado que sugere que "esta última perdeu parte considerável da sua influência e do seu prestígio nos últimos anos”. (ALBUQUERQUE, 2019, p. 18).

Esse processo que colocou em xeque o discurso da grande imprensa predispõe condições singulares para o avanço das mídias noticiosas evangélicas no Brasil. Proponho sondar esses efeitos pela observação do site Gospel Prime, criado em 2008 e transformado em um dos três maiores portais religiosos do país, com cerca de 2,8 milhões de leitores ao mês (BORGES, 2018). O site se apresenta como "um portal de conteúdo cristão focado em notícias gospel, estudos bíblicos e colunas de opinião", baseado na missão de "defender os princípios e valores do Reino" e "contribuir para uma igreja madura e contextualizada com os tempos". (QUEM SOMOS, 2021).

Gospel Prime integra uma cena de mídias digitais dedicadas ao segmento, como Gospel Mais, Pleno News, Guia-me e Verdade Gospel. Dentre esses concorrentes, o site se diferencia pela arquitetura, com seções que se assemelham às dos portais de notícia seculares: "Opinião", "Política", "Sociedade" ou "Cultura" (incluindo indicações de cinema, teatro, séries de TV etc.), somadas a outras de teor mais explicitamente religioso, como "Vida Cristã", "Estudos Bíblicos" ou "Devocional". A seção "Política" é exemplar do projeto do site: nela são dispostos conteúdos sobre a política institucional, desde que contenham algum dado considerado relevante para a audiência evangélica. Ou seja, em lugar de uma cobertura dos acontecimentos diários da política, como costumam oferecer os portais seculares, o site seleciona fatos que possam se tornar "notícias gospel". Gospel Prime coopera assim com aquele clima divisivo das guerras culturais ao visibilizar a política desde um "ponto de vista evangélico", notável em matérias como "Filha de Bolsonaro é batizada nas águas em cerimônia em Brasília" (CACERES, 2020a) ou "Associação indígena e PT vão ao STF contra missões em tribos isoladas". (CACERES, 2020b). 
O modelo de negócio de Gospel Prime está baseado em um sistema de publicidade conhecido como clickbait (ou caça-clique). Esse modo de faturamento consiste em rentabilizar o número de cliques recebidos por um link, o que condiciona as linhas editoriais dos sites a investirem em chamadas sensacionalistas como forma de atrair leitores. O clickbait determina assim uma seleção rigorosa dos títulos das notícias, mesmo que seu conteúdo não venha a corresponder ao apelo criado pela chamada.

Em 2017, o Monitor do Debate Político no Meio Digital, da Universidade de São Paulo, mostrou que o site foi um dos principais disseminadores de conteúdo enganoso a respeito de uma exposição realizada em uma escola estadual no Paraná, que acabou resultando em sindicância e investigação policial (MONITOR, 2017). O mesmo Monitor levantou que, nas eleições de 2018, uma matéria antiga veiculada por Gospel Prime teve intensa circulação, levando a crer que Fernando Haddad retomaria a proposta do Programa Brasil Sem Homofobia, que ficou conhecido como "kit gay". (POLICARPO et al., 2018).

Essas controvérsias fizeram Gospel Prime ser abordado em uma matéria de capa da revista Época em 2018, intitulada “O Exército de Pinóquios” e dedicada a mapear os sites que mais difundiriam notícias falsas no Brasil. Um desses boatos envolvia os nomes dos então Presidentes da República e da Câmara dos Deputados, Michel Temer e Rodrigo Maia, respectivamente, em um suposto desvio de verba pública para o financiamento de terroristas palestinos. A revista apurou que, além do faturamento com publicidade, o site era patrocinado por parlamentares evangélicos, como os Deputados Federais Sóstenes Cavalcante e Geovania de Sá, a fim de veicular conteúdos favoráveis à sua atuação.

Proprietário da empresa Prime Comunicação Digital, de Criciúma (SC), o publicitário Davi Gregório se posicionou sobre a inautenticidade de conteúdos no site alegando a existência de uma linha tênue entre informação e desinformação5: "tudo que eu publico, se tiver minha cosmovisão, se tiver meu modo de olhar esse

${ }^{5}$ Esse termo alude à difusão de informações falsas, boatos ou enganos, especialmente na internet. 
mundo, esse fato, pode ser chamado de fake news, porque não está na mídia mainstream". Por esse motivo, seguia, "algumas coisas que a gente publica também podem causar estranhamento, mas é porque a gente está vendo um ponto que a grande mídia não olha.” (BORGES, 2008). Após a publicação da matéria de capa de Época, Gospel Prime se defenderia das denúncias:

\begin{abstract}
Primamos pelo bom jornalismo. Atitude essa que a revista não teve em nenhum momento. Desde o início, não entrou em contato conosco de maneira clara para solicitar explicações ou oferecer direito de resposta. Pelo contrário. Mentiu se fazendo passar por estudante para depois usar as informações de maneira tendenciosa, pincelando fatos isolados. [...] Toda a equipe do site é cristã e tem compromisso com a verdade. Entre as milhares de matérias que já colocamos no ar, a Época foi capaz de encontrar apenas uma que não se encaixa no seu padrão e faz uma generalização absurda. Estamos em ano eleitoral e fica evidente que o objetivo da grande mídia é evitar o crescimento dos conservadores e quem dá voz a eles, como é o caso do Gospel Prime. (NOTA DE ESCLARECIMENTO, 2018).
\end{abstract}

O compromisso com a verdade como valor cristão era assim mobilizado como contraponto às parcialidades da matéria e, mais além, às escusas agendas da mídia tradicional. Se, como admite Gregório, o site publica "coisas que podem causar estranhamento" é porque "a gente está vendo um ponto que a grande mídia não olha”. Os elementos comentados fazem Gospel Prime despontar como expoente de um tipo de militância midiática que ascendeu na última década, e vem renovando as gramáticas da vida pública. A cena das chamadas "novas direitas" no Brasil se caracteriza por uma repaginação do pensamento conservador, para a qual concorrem tanto as especificidades de difusão e sociabilidade da comunicação online quanto o narcisismo político delas advindo. Nesse quadro, mídias como Gospel Prime, ao desobrigarem-se daquele remoto projeto de abrigar a "diversidade do pensamento evangélico brasileiro" e "unir a igreja", exacerbam a retórica do confronto com o panorama organizado pela sensibilidade secular.

O colunismo de Gospel Prime é um espaço fértil para a análise desse traço: o site conta com um elenco de mais de 70 articulistas voluntários. Segundo o proprietário, "essas pessoas acham que o Gospel Prime vai ser a vitrine do 
pensamento delas.” (BORGES, 2018). Um desses colaboradores em busca de reconhecimento é Maycson Rodrigues, "casado com Ana Talita, seminarista, pregador do evangelho, palestrante para família e casais, compositor, escritor, músico.” (RODRIGUES, 2019). Sua coluna no site, iniciada em 2016, revela uma característica distintiva das novas direitas brasileiras: o horror à "extrema imprensa”, termo que se popularizou entre os aliados do Presidente da República. Em 2019, por exemplo, o seminarista repudiou o tratamento dado pela mídia tradicional a uma postagem feita por Bolsonaro no Twitter, que chamava atenção para um ato obsceno ocorrido no Carnaval de rua de São Paulo, nesses termos:

Quero dar um recado à grande mídia, liderada pela TV Globo: deixem de ser hipócritas! [...] Outro recado importante: as últimas eleições provaram que não estamos mais reféns da grande mídia. Vocês não ditam mais as regras do jogo e as redes sociais continuarão a todo vapor. Acostumem-se com este dado da realidade! [...] Vocês aplaudiram o homem nu que - "em nome da arte" - foi tocado por uma criança. [...] Enquanto a ala progressista da sociedade cai em cima do presidente - dando um show de hipocrisia -, eu quero cair em cima da ala progressista da sociedade, pois o assunto "moralidade" nunca foi do interesse de vocês. Portanto, deixem de ser cínicos e parem de coar um mosquito enquanto engolem camelos e mais camelos. (RODRIGUES, 2019).

Aquele “imperceptível rio de opinião subterrâneo" parece ter vindo a desaguar em uma terrível "onda conservadora", ou melhor, em um ressentimento político versado em metáforas bíblicas, novo dado da realidade brasileira. As tendências populistas verificadas no país e no mundo indicam como a multiplicação dos públicos possibilitada pelas mídias na atualidade complexifica a tarefa das instâncias moderadoras da comunidade política. Dentre elas está a ideia de uma “opinião pública”, abstração moderna da qual a imprensa de prestígio foi o principal artífice histórico. Frente à crise dos meios tradicionais da comunicação e da política, o discurso reativo e beligerante de Gospel Prime é capaz de expor curtos-circuitos entre o secular e o religioso no Brasil recente, e as identidades e os interesses que conflitam com o público pressuposto por parcela influente da mídia tradicional. 


\section{Conclusão}

Diante das últimas evidências debatidas neste texto, é possível deduzir que o mercado das "variedades evangélicas", ao desbravar o terreno das mídias digitais, participa ativamente dos atuais processos de segmentação e polarização do debate político. As condições para esse acontecimento histórico nada têm de aleatórias, guardando afinidade direta com vocações propriamente evangélicas. Ao comentar a suscetibilidade desse público a notícias enganosas, Douglas (2018) nos lembra da longa história protestante de desconfiança quanto à neutralidade das instituiçoes seculares, como a academia, a imprensa e os órgãos de governo. Tal suspeita tem animado desde há muito, sustenta o autor, a criação de agências alternativas de produção e difusão da informação, como mídias e universidades, que oferecem um treinamento cognitivo religioso como resposta à recusa do conhecimento secular.

As mídias evangélicas aparecidas no contexto digital contam um novo capítulo da história desse sectarismo epistêmico. Ao contrário da simplicidade daquelas páginas religiosas da internet nos anos 2000, que se limitavam a exibir testemunhos e textos bíblicos, sites como Gospel Prime ocupam o meio digital com sofisticadas estratégias para captar atenção, cliques e publicidade, como parece requerer "uma igreja contextualizada com os tempos" (QUEM SOMOS, 2021). Apoiada em fake news e clickbaits, uma nova era midiática se anuncia para o segmento evangélico e potencializa círculos de difusão de conteúdo notavelmente endógenos. Tal fato tende a intensificar valores e crenças já adotados pela audiência e reduzir a experiência do contraditório, traço do debate que mídias impressas como Cristianismo Hoje chegaram a esboçar entre o segmento.

A análise das mídias evangélicas interessa também por sua diversificação editorial, que as leva a oferecer mais do que conteúdo caracteristicamente religioso. A noção de "notícia gospel" é exemplar nesse sentido: um tipo de informação sobre os "fatos do mundo" ao feitio da indústria cultural evangélica, em registro que funde entretenimento, fortalecimento do senso de grupo e crítica aos valores da sociedade mais ampla. Assim, sob o impulso das transformações midiáticas 
comentadas, a autoridade de que o jornalismo secular já gozou entre os evangélicos pode entrar em xeque. A experiência de marginalização do segmento quanto aos espaços e procedimentos que produzem a inteligibilidade do mundo público fomenta, nas mídias digitais, a crescente posicionalidade dos evangélicos em relação ao discurso secular.

O ódio à "extrema imprensa" aponta como públicos evangélicos podem se constituir pelo antagonismo ao discurso da mídia tradicional, um fenômeno descrito como contrapúblico. A noção de Warner (2002) permite pensar na identidade compartilhada por atores que se reconhecem em conflito com um horizonte cultural percebido como dominante. Não se trata, contudo, de uma mera divergência entre repertórios de ideias, mas de uma disputa pelos meios e formas através dos quais os diferentes discursos são hierarquizados pelas mídias. Contrapúblicos denunciam o estilo natural e correto de vida de um público refletido por um discurso dominante, com uma atitude que transforma os padrões tácitos que o organizam em objeto não apenas de crítica, mas de derrisão. Essa é a aparente lógica a guiar o proprietário de Gospel Prime: "tudo que eu publico, se tiver minha cosmovisão, se tiver meu modo de olhar esse mundo, esse fato, pode ser chamado de fake news, porque não está na mídia mainstream.” (BORGES, 2018). Em um portal cuja missão é “defender os princípios e valores do Reino” (QUEM SOMOS, 2021), conteúdos enganosos se autorizam como um modo de olhar o mundo que não consta na grande mídia.

Os conflitos inerentes ao secularismo brasileiro revistos neste texto permitem vislumbrar uma pequena genealogia daquela sensibilidade terrivelmente evangélica, performada como excesso e ameaça. As transições técnicas, éticas e políticas aqui destacadas fazem pensar nas muitas ambiguidades de um advérbio e de um tempo histórico capazes de alterar a intensidade e o modo dessa identidade religiosa em nossa vida pública. 


\section{REFERÊNCIAS}

ALBUQUERQUE, A. O papel da imprensa no debate público: impasses contemporâneos. Cadernos Adenauer, v. 10, 2019, pp. 11-25.

ALMEIDA, R. A onda quebrada - evangélicos e conservadorismo. Cad. Pagu [online], n. 50, e175001. Epub June 26, 2017.

ASAD, T. Formations of the Secular: Christianity, Islam, Modernity. Stanford University Press, 2003.

BAKKER, A. Entre telas e orações: religião e mídia em uma comunidade evangélica da Ilha Grande. Monografia de Conclusão de Graduação em Ciências Sociais, Universidade do Estado do Rio de Janeiro. Rio de Janeiro, 2006.

BALlOUSSIER, A. V. Eles escolheram esperar. Folha de São Paulo, São Paulo, 18 abr. 2014. Disponível em: < https://religiosamente.blogfolha.uol.com.br/2014/o8/18/elesescolheram-esperar// > . Acesso em: 23 fev. 2020.

BALlOUSSIER, A. V. No princípio era o verbo. Folha de São Paulo, São Paulo, 29 out. 2013a. Disponível em: < http://religiosamente.blogfolha.uol.com.br/2013/10/29/noprincipio-era-o-verbo/ >. Acesso em: 23 fev. 2020.

BAlloussier, A. V. Pergunte à Raíssa. Folha de São Paulo, São Paulo, 3 fev. 2015. Disponível em: < https://religiosamente.blogfolha.uol.com.br/2015/o2/o3/pergunte-araissa// > Acesso em: 23 fev. 2020.

BAlloUSSIER, A. V. Qual é a sua graça?. Folha de São Paulo, São Paulo, 4 nov. 2013 b. Disponível em: < https://religiosamente.blogfolha.uol.com.br/2013/11/o4/qual-e-a-suagraca// > Acesso em: 23 fev. 2020.

BIRMAN, P. (Org). Religião e espaço público. São Paulo: Attar Editorial, 2003.

BORGES, A. 'O Estado é laico, mas esta ministra é terrivelmente cristã', diz Damares Alves. O Estado de São Paulo, São Paulo, 2 jan. 2019. Disponível em: < https://politica.estadao.com.br/noticias/geral,o-estado-e-laico-mas-esta-ministra-eterrivelmente-crista-diz-damares-alves,70002664861 > Acesso em: 11 jan. 2021.

BORGES, E. Exército de Pinóquios. Época. 19 abr. 2018. Disponível em: < https://epoca.globo.com/brasil/noticia/2018/o4/o-exercito-de-pinoquios.html. > Acesso em: 27 fev. 2020.

BRANDÃO, J. Pastores que oprimem. Cristianismo Hoje, n. 11, pp. 18-20, jun./jul. 2009b.

BRANDÃO, J. Pesca de arrastão: Rede Evangélica Nacional de Ação Social mobiliza ativistas cristãos do Terceiro Setor. Cristianismo Hoje, n. 10, pp. 48-49, abr./mai. 2009a. 
BRUM, E. A dura vida dos ateus em um Brasil cada vez mais evangélico. Eliane Brum, 14 nov. 2011. Disponível em: < http://elianebrum.com/opiniao/colunas-na-epoca/a-duravida-dos-ateus-em-um-brasil-cada-vez-mais-evangelico/ > Acesso em: 24 fev. 2020.

CACERES, M. Associação indígena e PT vão ao STF contra missões em tribos isoladas. Gospel Prime, 15 dez. 2020b. Disponível em: < https://www.gospelprime.com.br/associacao-indigena-e-pt-vao-ao-stf-contra-missoesem-tribos-isoladas/ > Acesso em 11 jan. 2021.

CACERES, M. Filha de Bolsonaro é batizada nas águas em cerimônia em Brasília. Gospel Prime, 9 nov. 2020. Disponível em: < https://www.gospelprime.com.br/filha-debolsonaro-e-batizada-na-aguas-em-cerimonia-em-brasilia/ > Acesso em 11 jan. 2021.

CALDEIRA, R. C.; TONIOL, R. Catolicismo Eclipsado. Saída pela direita - Blog do Fábio Zanini - Folha de São Paulo, São Paulo, 31 jul. 2020. Disponível em: < https://saidapeladireita.blogfolha.uol.com.br/2020/o7/31/artigo-mostra-importancia-docatolicismo-para-ascensao-do-conservadorismo-no-brasil/ > Acesso em 03/01/2021.

CALGARO, F.; MAZUI, G. Bolsonaro diz que vai indicar ministro 'terrivelmente evangélico' para o STF. G1, 10 jul. 2019. Disponível em: < https://g1.globo.com/politica/noticia/2019/o7/10/bolsonaro-diz-que-vai-indicarministro-terrivelmente-evangelico-para-o-stf.ghtml > Acesso em 11 jan. 2021.

CAMPOS, L. S. Evangélicos, pentecostais e carismáticos na mídia radiofônica e televisiva. Revista USP, (61), 2004, pp. 146-163.

CAMURÇA, M. Um poder evangélico no Estado brasileiro? Mobilização eleitoral, atuação parlamentar e presença no governo Bolsonaro. Revista Nupem, v. 12, n. 25, 2020, pp. 82-104.

CARRANZA, B. Evangélicos: o novo ator político. In: GUADALUPE, J.; CARRANZA, B. (Org.). Novo ativismo político no Brasil: os evangélicos do século XXI. Rio de Janeiro: Konrad Adenauer Stiftung, 2020, p. 171-192.

CHAGAS, V. Uma alternativa para escapar à tabloidização ou uma forma de tabloidização alternativa? O mercado brasileiro de jornais populares e a economia política da imprensa escrita. Revista Brasileira de Ciência Política. Brasília, n. 22, jan./abr. 2017, p. 7-48.

COSTA, S. Contextos de construção do espaço público no Brasil. Novos Estudos CEBRAP, 47, pp. 179-192, 1997.

CUNHA, M. N. "Vinho novo em odres velhos": Um olhar comunicacional sobre a explosão do gospel no cenário religioso evangélico no Brasil. Tese de Doutorado em Comunicação, Universidade de São Paulo. São Paulo, 2004.

CUNHA, M. N. Elucidaç̃oes contemporâneas nos estudos brasileiros em mídia e religião: a perspectiva das mediaç,ōes culturais e comunicacionais. Revista Famecos: mídia, cultura e tecnologia. Porto Alegre, v. 23, n. 2, mai./ago. 2016a. 
CUNHA, M. N. Religião no noticiário: marcas de um imaginário exclusivista no jornalismo brasileiro. E-Compós, Brasília, v.19, n.1, pp.1-21, jan/abr 2016 b.

DOUGLAS, C. Religion and Fake News: Faith-Based Alternative Information Ecosystems in the US and Europe. The Review of Faith \& International Affairs, 16:1, pp. 61-73, 2018.

EFREM FILHO, R. "Os evangélicos" como nossos "outros": sobre religião, direitos e democracia. Religião e Sociedade, Rio de Janeiro, 39 (3), pp. 124-151, 2019.

FERNANDES, C. "Estão trocando o Evangelho de Cristo por um outro evangelho.

Cristianismo Hoje, out./nov. 2008, p. 56-58.

FERNANDES, C.; SIMAS, M. A Palavra em forma de revista. Ultimato. Belo Horizonte, 14 out. 2016. Disponível em: < https://www.ultimato.com.br/conteudo/a-palavra-em-formade-revista >. Acesso em: 26 fev. 2020.

FOUCAUlT, M. A Arqueologia do Saber. Rio de Janeiro: Forense Universitária, 2008.

FRESTON, P. Evangélicos na política brasileira. Religião \& Sociedade, Rio de Janeiro, v. 16, n. 1-2, pp. 26-44, 1992.

GONÇALVES JR., V.; SCHWENGBER, T. Inocentes sob risco. Cristianismo Hoje, n. 1, out./nov. 2007, pp. 10-14.

HABERMAS, J. Mudança estrutural da esfera pública: investigações quanto a uma categoria da sociedade burguesa. Rio de Janeiro: Tempo Brasileiro, 2003.

HIRSCHKIND, C. Existe um corpo secular? Religião \& Sociedade, v. 37, n. 1, 2017, pp. 175-189.

JUNGBLUT, A L. Os evangélicos brasileiros e a colonização da internet. Ciencias

Sociales y Religión/Ciências Sociais e Religião. Porto Alegre, ano 4, n. 4, p.149-166, out. 2002.

KIVITZ, E. R. Evangélicos, evangelicais e fundamentalistas. Cristianismo Hoje, n. 1, pp. 24-25, out./nov. 2007.

LUNA, N. A controvérsia do aborto e a imprensa na campanha eleitoral de 2010.

Cadernos CRH, vol.27, n.71, 2014.

MACHADO, L.; FERNANDES, C. O fantasma da intolerância. Cristianismo Hoje, n. 13, pp. 14-19, out./nov. 2009.

MARTINS, I.; ROCHA, L. A fé entrou na campanha. Época, São Paulo, 8 out. 2010. Disponível em: < http://revistaepoca.globo.com/Revista/Epoca/o,„EMI178504-15223,o0A+FE+ENTROU+NA+CAMPANHA.html > Acesso em 20 fev. 2020. 
MONITOR. Facebook, 2 nov. 2017. Disponível em: < https://ptfacebook.com/monitordodebatepolitico/posts/1582544085140382/> Acesso em 11 jan. 2021.

NOTA DE ESCLARECIMENTO. Gospel Prime. 20 abr. 2018. Disponível em < https://www.gospelprime.com.br/nota-de-esclarecimento-o-exercito-de-pinoquiosrevista-epoca/ > . Acesso em 28 fev. 2020.

OOSTERBAAN, M. “Escrito pelo Diabo': interpretações pentecostais das telenovelas”. Religião \& Sociedade. v. 23, n. 2, Rio de Janeiro: ISER, 2003.

PAULA, L.. Entre a Virtude e o Risco: sobre religião e opinião pública. Rio de Janeiro: Tese de Doutorado em Comunicação e Cultura, UFRJ.

POLICARPO, A. et al. A eleição do "kit gay”. Agência Pública, 17 out. 2018. Disponível em: < https://apublica.org/2018/10/a-eleicao-do-kit-gay/ > Acesso em 11 jan. 2021.

QUEM SOMOS. Gospel Prime. Disponível em: <

https://www.gospelprime.com.br/quem-somos > Acesso em: 11 jan. 2021.

REGA, L.. Evangélicos sob Inquisição. Vigiai.net. 7 out. 2013. Disponível em: $<$ http://vigiainet.com/artigos/lourenco-stelio-rega-evangelicos-sob-inquisicao-aumentana-sociedade-e-na-midia-o-patrulhamento-a-expressao-de-fe-crista-e-biblica $>$. Acesso em: 24 fev. 2020.

RODRIGUES, M. A hipocrisia da extrema imprensa. Gospel Prime. 6 de março de 2019. Disponível em < https://www.gospelprime.com.br/a-hipocrisia-da-extrema-imprensa/> Acesso em 28 fev. 2020.

SANT'ANA, R. A música gospel e os usos da "arma da cultura”: reflexões sobre as implicações de uma emenda. Revista Intratextos, Rio de Janeiro, v. 5, n. 1, pp. 23-41, 2013 .

SCHEWNGBER, T. Sala de casa, sala de aula. Cristianismo Hoje, n. 9, pp. 14, fev./mar. 2009b.

SCHWENGBER, T. Cabo de guerra no Congresso. Cristianismo Hoje, n. 2, pp. 8-12, dez. 2007/jan. 2008.

SCHWENGBER, T. Homens que ferem. Cristianismo Hoje, n. 10, pp. 14-16, mai./jun. 2009a.

SILVA, A. P. Nas tessituras do Império do Brasil: o protestantismo sob o olhar da imprensa periódica secular (1860-1870). Dissertação de Mestrado em História, Universidade Federal da Paraíba. Campina Grande, 2015.

SIMAS, M. Igreja, uma necessidade. Cristianismo Hoje, n. 19, pp. 7, out./nov. 2010. 
SIMAS, M. Informação com encorajamento, união e edificação. Cristianismo Hoje, n. 1, pp. 6, out./nov. 2007.

SINGER, S. Santo ou Satanás? Folha de São Paulo, São Paulo, 7 abr. 2013. Disponível em: < https://www1.folha.uol.com.br/fsp/ombudsman/102543-santo-ou-satanas.shtml > . Acesso em: 24 fev. 2020.

TORRES, H. B. O telejornalismo na construção da identidade religiosa: representaçóes evangélicas no Jornal Nacional e Jornal da Record e sua recepção por fiéis metodistas e batistas. Dissertação de mestrado em Comunicação, Universidade Federal de Juiz de Fora. Juiz de Fora, 2011.

URIBE, G. Bolsonaro diz que ministro 'terrivelmente evangélico' da AGU é bom nome para o STF. Folha de São Paulo, São Paulo, 11 jul. 2019. Disponível em: < https://www1.folha.uol.com.br/poder/2019/o7/bolsonaro-diz-que-ministroterrivelmente-evangelico-da-agu-e-bom-nome-para-o-stf.shtml > Acesso em 11 jan. 2021.

WARNER, M. Publics and Counterpublics (abbreviated version). Quarterly Journal of Speech, v. 88, n. 4, pp. 413-425, November, 2002. 